\title{
Method of Low-Carbon Energy Saving for Tunnel and Underground
}

\section{Project}

\author{
Yujian Xie \\ Civil engineering \& Architecture School, Linyi University, Linyi Shandong, 276005, China \\ xieyujian@lytu.edu.cn
}

Key words: tunnel, energy saving, low carbon, environmental resources

Abstract: At present, there exist some problems of energy conservation and emissions reduction in tunnel and underground engineering construction. During the operation period, the current situation of the energy conservation and emissions reduction in tunnel and all kind of underground space can not be ignored. Reducing the environmental impact of carbon emissions and other pollutants during the construction and operation of underground works, utilizing the natural resources adequately and reasonably, will further reduce the cost of energy conservation and emission reduction in tunnel and underground project and have far-reaching practical significance.

\section{Introduction}

To implement low carbon emissions reduction targets, it should reduce the dependence on fossil fuels such as coal and oil, increase the development and utilization of renewable energy like solar, wind, geothermal energy and so on, improve the efficiency of energy utilization in many aspects, and improve urban planning and further development of public transportation. In the current under the condition of low carbon economy,building all kinds of tunnel and underground spaces with resource-saving and environmentally friendly, plays an important and positive role in promoting about reducing the environmental pollution, promoting the underground engineering construction to develop roundly, harmonically and sustainably.

(1) The significance of energy saving and environmental protection of underground space.On the development of urban subway and underground roads, there are mainly reflected: considerably it can ease the flow of people on the ground and traffic on a large scale, including road vehicle emissions caused by urban air pollution, vehicle noise pollution and at night the light pollution, which can be greatly improved to a huge environmental protection effect; in addition, due to the warm in winter and cool in summer, relative to ground temperature and humidity variations are relatively small and significant energy-saving effect. The benefits of energy conservation environmental protection in this area is very impressive, but the effective use of the current situation is not enough, it still need to be further developed and perfected.

(2)Energy saving in tunnel lighting.Is the main lighting lamp with high power factor, for example: intelligent LED, on both sides of the tunnel laying high reflectivity of decoration materials, as far as possible to shorten the power supply cable length to reduce the line loss, reasonable layout of the location of the power distribution room, centralized automatic light control, reduce the brightness differences in hole method; in order to further save energy, the long tunnel of lamps and lanterns for the diurnal light, light of dusk, daylight lamp and emergency lights and other several loop were manual or automatic control. At the same time, to do a good job in saving energy, but also to study how to solve the problem of lighting, energy saves and traffic safety, and the contradiction between the three tunnel monitoring and so on. Underground space has a natural low carbon properties, it is 
in the building energy conservation, energy conservation and new energy use and other aspects of the ground buildings have unparalleled advantages. Various types of underground space development and utilization will bring urban carbon emissions more reduced. Accordingly, the establishment of energy-saving emission reduction of underground space quantization system and quantitative method; promote low carbon technology innovation and application, deepening of energy-saving design improvement and perfection, to achieve energy-saving technologies.

\section{Problems existing in energy saving and emission reduction in highway tunnel project}

Highway tunnel in tunnel lighting, mechanical ventilation, power supply and water supply and drainage and other major items of energy-saving emission reduction, the problem is mainly reflected in: in the implementation of energy-saving programs, the cost of inputs tend to have higher production efficiency, "energy-saving does not save money" contradiction, and whether it is worth investing in the confusion; flood the market under the banner of energy-saving under the banner of the fake and shoddy products, a number of energy-saving technology / product did not certified by the authority, huge investment is not to ensure the return on investment; the special funds for energy-saving emission reduction input is deficient, the relevant policies and regulations to support the implementation of the, energy-saving emission reduction is still in a low level of spontaneous behavior, implement inadequate.

(1)The main factors affecting energy saving and emission reduction. The highway tunnel is equipped with different functions according to its function, safety level, which is the most energy consumption of ventilation and lighting facilities. In terms of traffic operation, including traffic flow, traffic speed, traffic composition, transportation management, etc., the configuration of the subsidiary facilities in the tunnel also has important influence, and is closely related to. And different regional economic development level differences larger, the degree of awareness of energy-saving and emission reduction of transportation are not the same, which in a considerable extent also for energy conservation and emission reduction of the highway tunnel produced adverse effects; natural conditions in a certain extent will also of the highway tunnel of energy-saving emission reduction. In addition, the tunnel construction will also affect the mechanical and electrical facilities in a certain extent, which have an impact on energy saving and emission reduction in highway tunnel.

(2)Engineering measures and related technologies to implement energy saving and emission reduction in tunnel.To increasing the application ratio of "green energy" in highway tunnel, Lighting energy-saving emission reduction measures: the use of solar lighting and wind power generation, construct "complementary scenery" off grid power supply system, electric energy saving, reduce cost of power generation equipment allocation; ventilation energy-saving emission reduction means mainly includes: a feed forward ventilation control technology, double hole complementary type ventilation technology, air pollution electrostatic dust removal technology for air pollution soil purification technology; drainage energy saving emission reduction measures are mainly: application of fire water pump intelligent control technology, and efficient energy-saving water pump, selection of high strength and low friction hot galvanized steel pipe; strengthen and improve the management of energy-saving, for energy saving and emission reduction of road tunnel has extremely important guiding role.

\section{Strategy of energy saving and emission reduction in underground engineering}

The innovation direction of urban rail transit low carbon development.And gradually establish 
and improve the energy consumption evaluation index system, in order to promote the innovation and application of the low carbon energy saving technology; deepen the technological transformation of energy-saving design in traction system, inverter air conditioner, ventilation power, phased source; to strengthen and improve the energy-saving technology management, the implementation of the conservation and management of specific policies and measures.

\section{Energy saving and emission reduction measures in the operation period of tunnel and underground space}

(1)Tunnel lighting. The tunnel entrance, shed tunnel and saddle parts, the design of "skylight" to introduce natural light, using a variety of reflection and refraction of light rays into the mirror will make as much as possible to replace the underground cave, artificial lighting during the day; inside every several lamps installed "diffuse" lenses, the previously scattered light line around, using light absorption in the evening, the photosensitive material provides vehicle lighting less flow periods or emergency import hole; tunnel middle commonly used high intelligent LED lamp, generally replace the traditional early high-pressure sodium lamp and fluorescent lamp lighting; in the tunnel entrance section of the electrodeless enhanced lighting, automatic dimming technology, brightness and capture the outside the number of traffic flow as parameters, control the high intelligent automatic adjustment of LED lamp illumination; when necessary, and high pressure sodium lamp composed of light source, solve the hot and cold light source on the tunnel into the Estuary; application of electrodeless lamp, the service life of the equipment can be increased significantly, reduce energy consumption, new lighting energy-saving lighting products in China in recent years has diversified, but depreciation, and the quality of life to further improve the, there are still many improvements to do; into the optical fiber lighting is a introduction of natural light is a good way, no for energy conversion, the condensing element, acquisition, by the optical fiber transmission and convert sunlight directly into underground space.

(2)Subway and tunnel operation ventilation. Respectively peak in the morning and evening, night and normal operation of the three time periods, the broadband access server monitoring of subway ventilation and air conditioning, and set different ventilation mode; through computer setting program for tunnel ventilation intelligent control, in accidents and tunnel traffic congestion and other special sections, using artificial intervention start emergency plans, to adjust the ventilation inside the cave, the execution of different ventilation operation mode; not limited to the railway tunnel, highway longitudinal ventilation mode can also be effective use of piston wind, make the cave air is more economic and reasonable and effective automatic exchange, to achieve the maximum effect of energy-saving emission reduction.

\section{Reducing the environmental impact of carbon emissions and other pollutants during the construction and operation of underground works}

(1)Energy saving and emission reduction and environmental protection new technology application of tunnel shield water treatment system. Shield slurry waste recycling utilization, can reduce the environmental pollution; switching to natural soil made slurry, slurry treatment; equipment system can transplant technology; computer intelligent slurry management; mud recovery comprehensive treatment; sludge treatment system of sound insulation noise prevention, totally enclosed water mud and other measures.

(2)Adverse effects on water environment during tunnel construction.Tunnel mouth is provided with a water storage, sedimentation and filtration with a small pool, construction waste water after 
treatment and then; in the construction of seepage and water gushing is strictly prohibited discharged into surface water and sewer; such as hole endosmosis of gushing water and mud burst, the impact of local production and life to take sealing grouting and the second lining closed to reduce soil and water loss.

\section{Tunnel and underground space lighting energy saving technology}

Application of tunnel lighting energy saving technology. Use of lighting energy-saving controller to the development of lighting energy-saving control system according to the traffic parameters (vehicle flow, vehicle speed and the cave environment parameters (outside brightness), adaptive adjusting lamp brightness; especially to the import and export of strengthen the lighting section of automatically adjustable optical system and external tunnel illumination intensity and traffic to many corresponding, set the signal feedback device to ensure implemented traffic safety under the condition of the optimal degree of lighting lamps and lanterns.

The lights set partition (entrance section, transition section, middle section) control system. Especially when the holidays and night vehicle flow increase or decrease, as the automatic data acquisition and tracking to screening, automatically adjust the lighting brightness and the number of switching time, to reduce the energy consumption of lighting.

Select the appropriate lighting and reasonable installation angle. Optimization process increases the ceilings and walls light reflectance, tunnel roof, walls between the roads and can generate multiple reflection / refraction effect, can make the tunnel lighting reflected light increment coefficient than the untreated increases by about $20 \%$, to save more than $20 \%$.

Management and maintenance procedures should establish a long-term mechanism. Maintenance, especially check the gas discharge light source of reactive power compensation capacitor is not breakdown of light source and the attachment; in addition, the need to adjust the lighting control device, improve the lighting lamp maintenance coefficient, lighting system is always in good working condition.

\section{Conclusion}

At present, wall, floor, ceiling and other floor building with a certain function of phase transformation, which use building materials with a variety of phase change material inside, have better heat storage performance. The palisade structure of underground building will have enhanced thermal insulation and thermal storage by using the phase change material, and its energy utilization rate can be improved. The characteristic of the phase change material is: it can reduce the underground structure and rock and soil medium heat flux fluctuations, delay time, thereby reducing to the underground space heating and cooling air conditioning system design load and save energy costs; it can make the confined underground space be achieved supplement natural light by reasonable using optical fiber lighting; it can generate greenhouse effect an thermal effect by direct sunlight in the underground spaces which have the design of "square", is advantageous to the exhaust gas discharge, and can be designed as the auxiliary exhaust wind well; it can improve the heat storage capacity of the wall, reduce the heat load of underground space and the change of the temperature difference between the year and the month, improve the comfort of the indoor environment, and is beneficial to save the underground energy. 


\section{Reference}

[1] Tan Yizhong.Research progress of energy conservation and emission reduction in underground engineering[J]. Journal of underground space and Engineering,2010(S2).

[2] Dai Huaming.Rail transport energy saving low carbon development[J], Equipment supervision,2014(2).

[3] Wang Shaofei.Discussion on energy saving and emission reduction of highway tunnel [J]. Journal of the Institute of shipping transportation science,2011(1).

[4] Sun Jun, Peng Shixiong, Li Shufang.Energy saving and environmental protection of subway ventilation and the implementation of new technology [J].Journal of underground space and engineering,2012(S1). 